\title{
The Information System Mirror Approach and Knowledge Management Maturity Assessment
}

\author{
Boštjan Delak, ITAD - Audit and Consultancy, Ljubljana / Faculty of Information Studies, \\ Novo mesto, Slovenia, bostjan.delak@itad.si / delakb@fis.unm.si
}

\begin{abstract}
Nowadays, many organizations face the issues of information and communication technology (ICT) management and also issues related to knowledge management (KM). The organization undertakes various activities to assess the state of their ICT and KM. KM is vital for organizational progress and growth. $K M$ is often perceived as an instrument leading to innovation. This paper summarizes the research regarding IS maturity assessment and also KM maturity assessment within different organizations where the authors have delivered either complete IS due diligence or made partial analysis - IS Mirror. The main objective of this research is to present and confirm the approach which could be used for IS maturity assessment and could be provided quickly and remotely. The paper presents results from several case studies and confirms the proposed hypothesis.
\end{abstract}

Keywords: information system maturity, IS maturity assessment, knowledge management, knowledge management maturity, KM maturity assessment.

\section{Introduction}

Information and communication technology (ICT) supports most of the processes within the organization and therefore it is extremely important to manage this area. Information systems (IS) are much more than ICT, including the processes, data, documentation, and people - ICT professionals and IS end users as well. Stakeholders, management, and owners often wonder whether their system has sufficient quality and efficiency to meet the objectives, allow end user quality support for their daily operation and provide the management with sufficient information to make the right decisions. On the other hand, each process/production requires the coordinated efforts of individual specialists who possess many different types of knowledge (Grant, 1996). Drucker (1999) wrote that the most valuable asset of a 21st-century organization will be its knowledge, workers and their productivity. When explaining what knowledge is, Ragab and Arisha stated that "Knowledge is the currency of the current economy, a vital organizational asset and a key to creating a sustainable competitive advantage" (Ragab \& Arisha, 2013). Mäki (2008) define knowledge management (KM) as a flow of knowledge that ideally brings employee "right knowledge, at the right time, and in the right form to where it is needed". KM maturity is defined as "the extent to which KM is explicitly defined, managed, controlled, and effected" (Pee \& Kankanhalli, 2009).

The concept of maturity models is increasingly being applied within the field of IS, both as an informed approach for continuous improvement or as a means of benchmarking or selfassessment (Mettler et al., 2010). In 1984, the U.S. Department of Defense founded the Software 
Engineering Institute (SEI) to create a model of a more reliable software development process. With considerable industry assistance, SEI developed the Capability Maturity Model (CMM). More recently, SEI developed Capability Maturity Model Integration (CMMI)). It is a model consolidated from the bodies of knowledge (or domains of practice) that follow: software development, systems engineering, integrated product and process development and supplier sourcing (Esterhuizen et al., 2012). In 1998, the IT Governance Institute began an initiative on the subject of IT governance, focused on the COBIT framework, its processes, control objectives and maturity models (ITGI, 2004, p. 4). The CMMI practice has been integrated within all COBIT versions as per today. In 2016, ISACA acquired CMMI Institute (ISACA, 2016).

To obtain an independent report about the status of their IS and KM, some organizations perform different activities: IS or KM audit, IS or KM due diligence and also independent IS and KM analysis. Each of these activities also identifies the presence or lack of certain controls, noncompliance or other findings. Our position is that it is possible to make such an IS and KM assessment in an easy and fast way. Within the IS strengths and weaknesses analysis of the observed organization, it is possible to assess also the IS and KM maturity level within the observed organization. The approach with the IS and KM maturity assessment is explained in details within this paper. The remainder of our paper is structured as follows. Next section introduces the description of the scientific area and related problems. Then we present our motivation followed with a research hypothesis. Section five contains a literature review, followed by a description of our approach - evaluation and related methodology. Section seven presents the results followed by discussion, completed by concluding remarks.

\section{Description of scientific area and related problems}

Within this section the different approaches, methods and terminology such as Knowledge management, IS satisfaction, IS Maturity and KM maturity are described.

\section{Knowledge management}

Trkman and Desouza (2012) explained the difference between data, information, and knowledge by arguing that data are observed, raw, unanalyzed and uninterrupted patterns with no meaning; information is created through aggregation of data via the application of mathematical statistics, or logical processing techniques, and make sense of by the application of knowledge; while knowledge is the collection of experiences, know-how, expertise, and gut instincts that help us make sense of information. Becerra-Fernandez and Sabherwal (2015) define KM as "doing what is needed to get the most out of knowledge resources". Another simple definition of KM is "conscious strategy of getting the right knowledge to the right people at the right time and helping people share and put information into action in ways that strive to improve organizational performance" (O’Dell et al., 1998).

\section{Information system user satisfaction}

Every organization's owner and top management as well, are interested frequently measuring the IS success. DeLone and McLean (1992) described six major dimensions or categories of IS success: system quality, information quality, use, user satisfaction, individual impact and organizational impact. The stated dimensions are part of the DeLone and McLean IS success model. DeLone and McLean (1992) stated that user satisfaction - receipt response to the use of 
the output of an information system is probably one of the most widely used single measure of IS success. Petter et al. (2008) analyzed more than 180 papers found in the academic literature for the period from 1997 and 2007 dealing with IS success. They argued for user satisfaction that most widely used multi-attribute instrument for measuring user satisfaction can be found in Ives et al. (1983). Satisfaction of users with there IS is a potentially measurable, and acceptable, surrogate for utility in decision making (Ives et al., 1983). Ives used original Person's User information satisfaction instrument with 39 questions (Ives et al., 1983).

\section{Information system maturity}

In general, "maturity" can be defined as "the state of being complete, perfect or ready" (Simpson \& Weiner, 1989). All maturity models share the common property of defining a number of dimensions at several stages of maturity, with a description of characteristic performance at various levels of granularity (Fraser et al., 2002). The purpose of maturity models is to give guidance through an evolutionary process by incorporating formality into the promising improvement activities. To measure dedicated aspects of maturity, a wide range of maturity models has been developed in the field of IS by both, practitioners and academics over the past years (Mettler \& Rohner, 2009).

\section{Knowledge management maturity}

KM maturity is defined as "the extent to which KM is explicitly defined, managed, controlled, and affected" (Pee \& Kankanhalli, 2009). CMM was inspired by Total Quality Management, which is a means for improving personal effectiveness and performance and for aligning and focusing all individual efforts throughout an organization. It provides a framework within which you may continuously improve everything you do and affect. (Mansir \& Schacht, 1989, p. 1-1). CMM framework represents a path of improvements to increase software process capability. CMM defines five progressively more "mature" forms of the software development process, from Level 1 - initial, through repeatable, defined, and managed, to Level 5 - optimizing (Paulk et al., 1993). Maturity models have been adopted in various areas of knowledge are based on two theories: the Knowledge-based View and Life Cycle Theory (Oliveira \& Pedron, 2014). Oliveira and Pedron (2014) analyzed seven KM maturity models (Lee and Kim (2001), North and Hornung (2003), Robinson et al. (2006), Mehta et al. (2007), Pee \& Kankanhalli (2009), Khatibian et al. (2010) and Oliveira et.al. (2011). Analyzed KM maturity models did not associate KM with strategic benefits such as absorptive capacity, innovation and organizational performance ((Oliveira \& Pedron, 2014). Ragab and Arisha (2013) identified the need to improve the methods of measuring KM results.

\section{Motivation}

Different types of IS analysis require human resources and the presence of experts at the client's location. With the objectives to carry out a brief but effective IS analysis of the inspected organization, we have prepared a special method for such an activity entitled the IS Mirror method (Delak, 2015). One of the objectives of the IS analysis is also to assess the IS maturity 
level and KM maturity level of the observed organization. Our motivation is to evaluate this approach to assess the KM maturity level from the data gathered from the IS Mirror method.

\section{Research question}

Our research question is:

Can be a KM maturity level assessment provided by analyzing data gathered from an IS Mirror method?

We intend to validate the research question by confirming the approach to KM assessment as a design research (Hevner et al., 2004) and to evaluate and demonstrate this IT artifact by observational methods with case and field studies. Hevner et al. (2004) defined several guidelines for design-science research, such as: Design as an artifact, Problem relevance, Design evaluation, Research contribution, Research rigor, Design as a search process and Communication of research. During the paper, we have followed these guidelines.

\section{Review of the literature}

Determining what makes an IS successful is an ongoing concern for both researchers and practitioners alike. Measuring success within the IS has been a concern for those within the discipline since its inception (Behrens et al., 2005). In the second half of 80's Davis developed the Technology Acceptance Model, and eventually became the most used theoretical models in the field of IS (Lee et al., 2003). DeLone and McLean (1992) developed the DeLone and McLean model of IS success based on six dimensions: system quality, information quality, users, user satisfaction, individual impact, and the impact on the organization. Seddon's respecification of the DeLone and McLean's model assumed that different individuals are likely to evaluate the consequences of the IS used in different ways as: "IS Success is thus conceptualized as a value judgement made by an individual, from the point of some stakeholder" (Seddon, 1997). Zviran and Erlich (2003) emphasized that measuring the success of IS increases with the importance and involvement of IS in the organization.

The term "due diligence" usually refers to a specific activity during the merger and acquisition process. Due diligence is one method of getting the necessary information and knowledge of existing IS. Bhatia (2007) explained how important it is to follow a structured framework in IS due diligence activities. The IS field lacks a scientifically based analytical tool for rapid delivery of IS due diligence. Delak and Bajec (2013) presented an approach - the framework for IS due diligence (FISDD). The FISDD also contains a questionnaire to gather information on the pros and cons titled FISDD IS Strengths and weakness questionnaire. It consists of 58 questions within 8 groups: Productivity of the IS, Quality of the existing application system, Effective use of technology, Information security (confidentiality, integrity, availability information), Usage of the advanced and modern technologies, ICT employees, Cooperation between end users and ICT, Participation of ICT in projects. This questionnaire also measures user information satisfaction, as stated by Ives et al. (1983). The FISDD IS Strengths and weakness questionnaire covers most of the items presented in the user information satisfaction instrument presented by Ives et al. One of the FISDD novelties is online FISDD IS Strengths and weaknesses questionnaire, which is described in the paper titled "Novelties within the Framework for 
Information System Due Diligence" accepted by one journal and will be published in the second half of 2016. This online questionnaire could also be used as standalone ICT artifact - IS Mirror (Delak, 2015).

On the other hand, by reviewing certain scientific papers, the authors observed descriptions of the various methods for evaluating the effectiveness, quality, and benefits of IS. Sedera and Tan (2005) pointed out that the satisfaction of end users is the most widely used dimension to ensuring the success of IS; their findings based on next characteristics: the quality of information, the quality of the system, the impact on the individual, and the impact on the organization. Becker et al. (2010) argued that research on maturity models is of growing interest, they also stated: "while maturity models have been addressed in prescriptive, descriptive and reflective works, the notions of maturity and maturity models have rarely been conceptualized in detail." Wulf et al. (2015) argued that maturity models describe stages of evolutionary improvement in a specific process or domain and maturity models do not cover only the extensive definition of organizational routines, but also the performative perspective and are therefore also used to describe the level of organizational capability. Fraser et al. (2002) described that maturity models have been proposed for a range of activities including quality management, software development, supplier relationships, product development, innovation, product design, collaboration, product reliability, and knowledge management. Fraser also described the principle idea of the maturity grid in that it describes IS in a few phases, the typical behavior of the organization at a number of levels of maturity, for each of several aspects of the area under study. Kumta and Shah (2002) discussed that measurement of product quality and process maturity is used constructively to evolve the quality culture in the organization.

Oliveira and Pedron (2014) made a review of eight different KM maturity models. Another review was made by Chan et al. (2012) describing: Knowledge navigator model, Gallagher and Hazlett's model, and Collins and Parcell's KM framework. In debating "how" to measure KM's institutionalization, it is of interest to note that Klimko (2001) argues that maturity modeling is an evolutionary and a generic approach describing the development of an entity over time, progressing through different levels of maturity towards a usually idealistic ultimate state.

\section{Approach}

Hevner et al. (2004) suggested several guidelines for design science. The IS Mirror is an ICT artifact, since it describes a method for analyzing IS strengths and weaknesses (Delak, 2015). The further development of this approach is based for a detailed description of the evaluation of the maturity level of observed organization. This approach has been evaluated by several case studies described in this chapter. Our aim is to assess the knowledge management maturity level of observed organization based on analyzing data gathered from the IS Mirror approach.

\section{IS Mirror}

The IS Mirror is a web-based questionnaire to gather information on the pros and cons of observed IS. It is one of the FISDD novelties, as described earlier. IS Mirror can be used as a standalone analysis tool or as part of the framework for IS due diligence. The IS Mirror's respondents are IS end users within the observed organization, and ICT specialist (either employed in the observed organization or external, when the observed organization outsources 
specific services). Each respondent first assesses whether the item to which the question refers is an advantage [+] or a disadvantage [-]. Then give a numerical value, which can be for "strength" / advantage site from +5 [ideal / cannot be better] to +1 as the minimum strength. If the item is in a "weaker" /disadvantage site, estimates can be from -1 [minimal weakness] to -5 [worst / cannot be worse]. If the respondent does not have the experience or cannot answer a question, then give the mark 0 and comments it. The respondent can enter the reason for giving the mark [for example: I cannot identify the answer, I do not have experience, I do not know the area]. The responses could be presented as enlarged Likert scale (Table 1).

Table 1. Enlarged Likert Scale

\begin{tabular}{|l|c|}
\hline Statement & Mark / numeric value \\
\hline Absolutely agree & 5 \\
\hline Strongly agree & 4 \\
\hline Agree & 3 \\
\hline Somehow agree & 2 \\
\hline Minimally agree & 1 \\
\hline Neutral $(*)$ & 0 \\
\hline Minimally disagree & -1 \\
\hline Somehow disagree & -2 \\
\hline Disagree & -3 \\
\hline Strongly disagree & -4 \\
\hline Absolutely disagree & -5 \\
\hline
\end{tabular}

* I cannot identify the answer, I do not have experience, I do not know the area

As there are several types of maturity levels, and Wulf et al. (2015) mentioned some of them CMMI-SVC, COBIT 4.1, SPICE, ITIL v3, we have chosen COBIT 4.1 (ITIG, 2009) maturity modeling, as we have experienced while we are daily using COBIT maturity modelling of the audit activities. This approach is derived from the maturity model that the SEI defined for the maturity for software development capability. Maturity modelling for management and control over IT processes is based on a method of evaluating the organization so that it can be rated from a maturity level of non-existence (0) to optimized (5). Table 2 presents all six maturity levels, the COBIT maturity model has.

The IS maturity level of observed organization is calculated from the analysis outputs of data gathered by IS Mirror approach. For each of 8 groups of questions, the absolute maximal difference between average end users mark and average ICT specialist mark is identified. This value is compared with the difference and for each group chooses the specific weight presented in Table 3. Our weighting approach is based on next figures, as COBIT 4.1 maturity model has six levels; we have linearly split the strength or weakness (the half value of the enlarged Likert scale). 


\section{Table 2. Generic maturity model from COBIT}

\begin{tabular}{|l|l|}
\hline Level & Description \\
\hline 0 - Nonexistent & $\begin{array}{l}\text { Complete lack of any recognizable processes. The enterprise has not even } \\
\text { recognized that there is an issue to be addressed. }\end{array}$ \\
\hline Hoc Initial / Ad & $\begin{array}{l}\text { There is evidence that the enterprise has recognized that the issues exist } \\
\text { and need to be addressed. There are, however, no standardized processes; } \\
\text { instead, there are ad hoc approaches that tend to be applied on an } \\
\text { individual or case-by-case basis. The overall approach to management is } \\
\text { disorganized. }\end{array}$ \\
\hline $\begin{array}{l}\text { but - Repeatable } \\
\text { butuitive }\end{array}$ & $\begin{array}{l}\text { Processes have developed to the stage where similar procedures are } \\
\text { followed by different people undertaking the same task. There is no formal } \\
\text { training or communication of standard procedures, and responsibility is left } \\
\text { to the individual. There is a high degree of reliance on the knowledge of } \\
\text { individuals and, therefore, errors are likely. }\end{array}$ \\
\hline Process & $\begin{array}{l}\text { Procedures have been standardized and documented, and communicated } \\
\text { through training. It is mandated that these processes should be followed; } \\
\text { however, it is unlikely that deviations will be detected. The procedures } \\
\text { themselves are not sophisticated but are the formalization of existing } \\
\text { practices }\end{array}$ \\
\hline $\begin{array}{l}\text { Management monitors and measure compliance with procedures and takes } \\
\text { and Measurable }\end{array}$ & $\begin{array}{l}\text { action where processes appear not to be working effectively. Processes are } \\
\text { under constant improvement and provide good practice. Automation and } \\
\text { tools are used in a limited or fragmented way. }\end{array}$ \\
\hline 5 - Optimized & $\begin{array}{l}\text { Processes have been refined to a level of good practice, based on the } \\
\text { results of continuous improvement and maturity modelling with other } \\
\text { enterprises. IT is used in an integrated way to automate the workflow, } \\
\text { providing tools to improve quality and effectiveness, making the enterprise } \\
\text { quick to adapt. }\end{array}$ \\
\hline
\end{tabular}

Source: COBIT 4.1 (ITGI, 2009, page 19)

Table 3. Maturity weight index

\begin{tabular}{|c|c|}
\hline The difference between & Weight \\
\hline $0,00-1,00$ & 6 \\
\hline $1,01-2,00$ & 5 \\
\hline $2,01-3,00$ & 4 \\
\hline $3,01-4,00$ & 3 \\
\hline $4,01-5,00$ & 2 \\
\hline More than 5,01 & 1 \\
\hline
\end{tabular}

This weight search is repeated for each of questionnaire groups. The final maturity level value is calculated by the next formula:

$$
\alpha=\left(\left(\sum_{\mathrm{k}=1}^{\mathrm{n}} \mathrm{x}_{\mathrm{k}}\right) / \mathrm{n}\right)-1
$$


Where:

$\alpha$ - is the maturity value,

$\mathrm{n}$ - is the number of questionnaire groups (in our case 8),

$\mathrm{x}$ - is the weight for each group of questions.

The FISDD has within FISDD IS Strengths and weaknesses questionnaire 58 questions within eight groups. The IS Mirror used these questions within the web-based questionnaire. We have not developed a special KM group of questions for KM maturity level assessment. For this study, we have used question within the IS Mirror's "Effective use of technology group" of questions there is one question related to KM: "Assess the maturity of knowledge management within your organization." The average mark from both sides, IS end users and ICT specialists to this KM question gathered from IS Mirror is then transferred to the maturity level scale (from 0 to 5). We simplify the KM maturity level assessment.

\section{Case studies}

From 2013 to 2015, we conducted several IS Mirror analysis of different organizations in Slovenia. The purpose of the case studies was to verify the validity of the assessment of observed organizations IS maturity level and also to verify the validity of the knowledge management maturity assessment of observed organization. By this methodology, we would like to carry out certain rules or conclusions, and get answers to our research question.

\section{Participants}

For the case studies, we have selected 5 IS Mirror analysis realized in Slovenia in different organizations from different industries (such as: company producing hand tools, hydro institute, government organization, manufacturing company, electricity organization). The size of observed organization varied from 80 to 2.500 employees (Table 4).

Table 4. Description of case studies organization

\begin{tabular}{|l|c|c|}
\hline Industry & Number of employees & Number of ICT specialists \\
\hline Hand tools producer & 2.500 & $50(20+30)^{*}$ \\
\hline Hydro institute & 100 & $8(2+6)$ \\
\hline Government organization & 200 & $15(3+12)$ \\
\hline Manufacturing & 150 & $10(2+8)$ \\
\hline Electricity organization & 80 & $20(5+15)$ \\
\hline
\end{tabular}

$* a(b+c)->a=$ ICT specialists total number, $b=$ number of internal ICT specialists, $c=$ number of external ICT specialists 


\section{Procedure}

The gathered data for the analyses have been collected only by IS Mirror approach. The initial objective was to deliver IS analysis regarding IS strengths and IS weaknesses within an observed organization. The objectives for the organization IS analyses have been different (general IS due diligence, IS audit and IS analysis). The details are described in Table 6. Within these analyses also the IS maturity levels have been calculated. The knowledge management maturity level of the case study organization has been calculated later as the research study.

The average time for respondents to complete IS Mirror questionnaire is 45 minutes when most of the respondents took 30 to 40 minutes to complete it. The online questionnaire has a "help" selection for each question, to provide more detailed explanation about the question.

\section{Data analysis}

All gathered data from online questionnaire have been input to the Excel tables. For each case study, a separate document has been created. The maturity level is calculated within three steps. First with simple Excel functions calculate average marks for IS end user side and average marks for ICT specialist side. Second the maximum difference from both sides for specific questionnaire subgroup has been identified and the level weight from table 3 has been selected. Third the above mentioned mathematical formula has been used to calculate IS organization's maturity level.

On the other hand, for the knowledge management maturity level the data analysis is straightforward. For specific knowledge management question, the Excel function identifies an average mark for IS end user side and average mark for ICT specialist side. The common knowledge management mark is a simple sum of both divided by two. The mark's range could theoretically be from -5 up to +5 and the common knowledge management mark is then transformed to six maturity levels from 0 - nonexistent in 5 - optimized.

\section{Results}

The IS Mirror approach for data gathering is using the web-based questionnaire (Survey Monkey - www.surveymonkey.com). This study attempts to confirm the approach for IS maturity level assessment and also KM maturity level assessment.

The data have been gathered from five analyses within the period of three years within one country in Central Europe - Slovenia. All five observed organization came from different industries. The collected data have been used for the case studies.

Table 5 presents average marks for all eight questionnaire's groups for one organization (case study) - Hydro institute. On one hand, for IS end users average marks, and on the other for ICT specialist average marks. In the column "maximal difference" the maximal difference within one subgroup are presented. These values are the basis for each group's weight selection. Calculated IS the maturity level of the formula mentioned above for this organization presented is 0.63 , interpreted by textual maturity level from table 2 as between 0 - Nonexistent and 1 - Initial / Ad Hoc. 
Table 5. Average marks, gathered by IS Mirror from one organization

\begin{tabular}{|l|c|c|c|}
\hline Questionnaire group & $\begin{array}{c}\text { End Users } \\
\text { Marks }\end{array}$ & $\begin{array}{c}\text { ICT Specialists } \\
\text { Marks }\end{array}$ & $\begin{array}{c}\text { Maximum } \\
\text { difference }\end{array}$ \\
\hline Productivity of the IT & 0.84 & $-0.67^{*}$ & 3.29 \\
\hline The quality of the existing application system & 0.26 & 0.36 & 5.30 \\
\hline Effective use of technology & 1.57 & 4.33 & 5.85 \\
\hline $\begin{array}{l}\text { Information Security [confidentiality, } \\
\text { integrity, availability] }\end{array}$ & 1.39 & 2.22 & 7.00 \\
\hline Using the advanced and modern technologies & $-1.16^{*}$ & $-2.83^{*}$ & 5.55 \\
\hline Employees of the department of Informatics & 0.83 & $-2.17^{*}$ & 4.28 \\
\hline $\begin{array}{l}\text { Cooperation between users and employees in } \\
\text { the department of Informatics }\end{array}$ & 0.26 & $-0.56^{*}$ & 2.42 \\
\hline $\begin{array}{l}\text { Participation of the department of Informatics } \\
\text { at the projects }\end{array}$ & 0.03 & 1.58 & 2.91 \\
\hline Average & 0.50 & 0.28 & \\
\hline
\end{tabular}

* - Minus sign means weakness.

Table 6 presents maturity levels either for IS maturity level and knowledge management maturity level of all five case studies.

Table 6. Details from the Case Studies and Maturity Level Results

\begin{tabular}{|l|l|c|c|c|c|}
\hline Industry & Country & Year & $\begin{array}{c}\text { Task / } \\
\text { Activity }\end{array}$ & $\begin{array}{c}\text { IS } \\
\text { maturity } \\
\text { level }\end{array}$ & $\begin{array}{c}\text { KM } \\
\text { maturity } \\
\text { level }\end{array}$ \\
\hline Hand tools producer & Slovenia & 2015 & $\begin{array}{c}\text { General IS } \\
\text { due diligence }\end{array}$ & 2,86 & 3,24 \\
\hline Hydro institute & Slovenia & 2014 & IS analysis & 0,63 & 2,65 \\
\hline Government organization & Slovenia & 2014 & IS audit & 1,88 & 2,48 \\
\hline Manufacturing & Slovenia & 2013 & IS analysis & 2,75 & 2,88 \\
\hline Electricity organization & Slovenia & 2013 & IS analysis & 2,38 & 1,95 \\
\hline
\end{tabular}

\section{Discussion}

Zviran and Erlich (2003) wrote that the user satisfaction factor is an important criterion and the one most prevalent for measuring the success of IS. Mettler and Rohner (2009) argued that the popularity of maturity models was especially intensified by the introduction of the CMM. IT Governance Institute (ITGI, 2008) did a study with one objective: Collect, process maturity data from a wide variety of enterprises to develop preliminary benchmarks for each maturity attribute/IT process combination. The ITGI study covers 51 companies from 8 countries (Austria/Germany/Switzerland, Canada, Mexico, Philippines, Singapore and the USA) and five different industries. The average IS maturity level in ITGI study is 2.4 which is comparable with average IS the maturity level of our case studies 2.10. These findings unofficially confirm our 
hypothesis that with our approach we can assess the IS maturity level of the observed organization.

On the other hand, we are unable to find practical case studies describing KM maturity levels. De Bruin et al. (2005) proposed a generic methodology for the development of maturity models in various domains. They also argued that the value in a generic methodology lies in the ability to develop a model that is highly generalizability and enables standardization. Our case studies show that our IS maturity level assessment is highly generalizable, and the results are comparable ITGI research.

\section{Interpretation of the findings}

The web-based questionnaire (IS Mirror) has been used within the last three years (2013-2015). Our analysis identified that the data gathered by the IS Mirror have less 0 marks, expressing respondent's status - "I cannot identify the answer", "I do not have experience", "I do not know the area", then collected manually by the IS due diligence processes. These might be the result of the help facility within the IS Mirror, giving an additional explanation of the related question. Within the questionnaire, there is only one question related to KM. Based on our expression KM maturity levels of case studies are in majority higher than evaluating IS maturity levels. Only eclectic company assessed KM maturity level is lower than IS maturity level. Interesting is that the highest maturity level was assessed in "Hand tool producer" organization, which has more than 100 years old tradition and also constant monitoring and stimulating new ideas, patents and very high level of intellectual capital.

\section{Implication of the study}

Zviran and Erlich (2003) defined some conclusions and recommendations, we have tried to integrate these in our approach to IS satisfaction evaluation with emphasis on the pros and cons, the evaluation from both IS sides, the evaluation from IS end users and the evaluation from internal IS service providers. As Seddon et al. (1999) argued that different measures are likely to be needed to assess the impact of effectiveness of system for different groups of stakeholders, we have integrated such as measures of the IS Mirror. Becker et al. (2010) have stated: "Maturity models are a theme of growing importance in the IS discipline" - within our paper and related case studies, we confirm Becker's another statement: "Maturity and maturity models have rarely been conceptualized in detail and can be regarded as scientifically underdetermined" - with our paper we try to lower this gap for IS maturity level, on the other hand, we try to evaluate the approach for KM maturity level assessment, which is very basic and requires appropriate upgrades. The IS Mirror has to be upgraded with KM specific questions and further activities to proof this approach has to be made.

\section{Limitation of the study}

Several factors should be considered before fully confirming this approach as a general approach to IS maturity level assessment and also approach for KM maturity level assessment as well. First, the case studies were released only in Slovenia. Second, we have not assessed the IS maturity level of observed organizations with other methodologies, tools, approaches or standards for IS maturity level assessment to compare the results. Third, we have not assessed 
the KM maturity level of observed organizations with other methodologies, tools, or approaches for KM maturity level (e.g. methods presented by Oliveira \& Pedron (2014)). Fourth, the webbased questionnaire (IS Mirror) has been proven in the organization with up to 2,500 employees and fifty the assessment with only one question is weak.

\section{Conclusion}

The purpose of this paper was to explore an approach to assess IS maturity level and KM maturity level in the observed organization. This paper investigates the research question: Can be a KM maturity level assessment provided by analyzing data gathered from an IS Mirror method? The proposed approach is an IS artifact, and we have followed Hevner et al. (2004) guidelines to validate the approach. Our approach is based on COBIT maturity levels. ITGI has presented similar results (2008) for IS maturity as we have gotten with our Case studies. Our research clearly shows that IS maturity level can be evaluated within a short period of time, by IS Mirror approach. On the other hand, we were unable to compare the results of KM maturity level assessment. We are unable to confirm the research question; reasons were presented in the limitation section.

The paper presented the IS Mirror as an approach for fast IS maturity level assessment, but for completeness and generalized approach, the questionnaire has to be upgraded with KM domains and validated by additional case studies and other methods.

Our future research topic in this area will be to enlarge IS Mirror approach with additional KM questions and as well to academic theories, and develop a theoretical foundation for this approach. Our additional future work includes some parallel analysis, IS Mirror with other methods for KM maturity level assessment, and also parallel analysis of our approach with other methods for KM evaluation within one organization.

\section{Acknowledgement}

I would like to thank to the management of the company ITAD Auditing and consulting, Ljubljana, Slovenia, which enabled me to carry out the analysis of IS Mirror and allowed me to publish the results in the context of this paper. I would like to thank also to my colleague Mr. Tevž Delak, who made first comments about this paper. I would like to thank to KM2016 reviewers, who gave me comments and suggestions, how to improve this paper.

\section{References}

Becerra-Fernandez, I., \& Sabherwal, R. (2015). Knowledge Management Systems and Processes. Routledge, Taylor \& Francis Group, New York, USA.

Becker, J., Niehaves, B., Poeppelbuss, J., \& Simons, A. (2010). Maturity model in IS Research, Proceedings of 18th European Conference on Information Systems, Paper 42.

Behrens, S., Jamieson, K., Jones, D., \& Cranston, M. (2005). Predicting System Success using the Technology Acceptance Model: A Case Study, Proceedings of the 16th Australasian Conference on Information Systems, Sydney, Australia. 
Bhatia, M. (2007). IT Merger Due Diligence - A Blueprint, Information System Control Journal, $1,46-49$.

Chan, K.H., Chu, S.K.W., \& Wu, W.W.Y. (2012). Exploring the correlation between Knowledge Management maturity and Intellectual Capital efficiency in Mainland Chinese listed companies, Journal of Information \& Knowledge Management, 11(3).

De Bruin, T., Freeze, R., Kulkarni, U. \& Rosemann, M. (2005). Understanding the Main Phases of Developing a Maturity Assessment Model, Proceedings of 16th Australasian Conference on Information Systems.

Delak, B., \& Bajec, M. (2013). Framework for the Delivery of Information System Due Diligence, Information Systems Management, 30(2),137-149.

Delak, B. (2015). Information System Mirror - Approach How to Analyze Information System Strengths and Weaknesses within Organization. In: Kadunc, T. (ed.) Social sciences via network analysis and computation, 69-78, Peter Lang. Frankfurt am Main, Germany.

DeLone, W.H., \& McLean, E.R. (1992). Information System Success: The Quest for the Dependent Variable, Information System Research, 3(1), 60-95.

Drucker, P. F. (1999). Knowledge-worker productivity: The biggest challenge, California management review, 41(2), 79-94.

Esterhuizen, D., Schutte, C., \& Du Toit, A. (2012). A knowledge management framework to grow innovation capability maturity, SA Journal of Information Management, 14(1), Art. \#495.

Fraser, P., Moultrie, J., \&, Gregory, M. (2002). The use of maturity models/grids as a tool in assessing product development capability, IEEE international engineering management conference, Cambridge, UK.

Grant, R. M. (1996) Prospering in dynamically-competitive environments: Organizational capability as knowledge integration, Organization Science, 7(4), 375-387.

Hevner, A., March, S., \& Ram, S. (2004). Design Science in Information System Research, MIS Quarterly, 28(1), 75-105.

ISACA. (2016). ISACA Acquires Global Capability Maturity Leader CMMI@ Institute. Press Release by ISACA on March $3^{\text {rd }}$. Retrieved April 6, 2016, from http://www.isaca.org/About-ISACA/Press-room/News-Releases/2016/Pages/ISACAAcquires-Global-Capability-Maturity-Leader-CMMI-Institute.aspx.

ITGI. (2004). COBIT Mapping - Mapping of ISO/IEC 17999:2000 with COBIT, Information Technology Governance Institute, IL, Rolling Meadows, USA.

ITGI. (2008). IT Governance and Process Maturity, Information Technology Governance Institute, IL, Rolling Meadows, USA.

ITGI. (2009). COBIT 4.1 - Framework, Control Objectives, Management Guidelines and Maturity Models, Information Technology Governance Institute, IL, Rolling Meadows, USA. 
Ives, B., Olson, M., \& Baroudi, J.J. (1983). The measurement of user information satisfaction, Communications of the ACM, 26(10), 785-793.

Khatibian, N., Hasan, T., \& Jafari, H.A. (2010). Measurement of knowledge management maturi ty level within organizations, Business Strategy Series, 11(1), 54-70.

Klimko, G. (2001). Knowledge Management and Maturity Models: Building Common Understanding, Proceedings of the 2nd European Conference on Knowledge Management, 269-279.

Kumta, G.A., \& Shah, M.D. (2002). Capability Maturity Model A Human Perspective, Delhi Business Review, 1.

Lee, J.H., \& Kim, Y.G. (2001). A stage model of organizational knowledge management: a latent content analysis, Expert Systems with Application, 20(4), 299-311.

Lee, Y., Kozar, K.A., \& Larsen, K.R.T. (2003). The Technology Acceptance Model: Past, Present, and Future, Communications of the Association for Information Systems, 12(50), 752-780.

Mäki, E. (2008). Exploring and Exploiting Knowledge. Research on Knowledge Processes In Knowledge-Intensive Organizations, $\mathrm{PhD}$ Thesis, Helsinki University of Technology.

Mansir, B. E., \& Schacht N.R. (1989). Total Quality Management - A Guide to Implementation, Logistics Management Institute, Bethesda, USA.

Mehta, N, Oswald, S, \& Mehta, A. (2007). Infosys Technologies: improving organizational knowledge flows, Journal of Information Technology, 22(4), 456-464.

Mettler, T., Rohner, P., \& Winter, R. (2010). Towards a Classification of Maturity Models in Information Systems. In: D’Atri et al. (eds.) Management of the Interconnected World, 333-340, Springer-Verlag Berlin Heidelberg, Germany.

Mettler, T., \& Rohner, P. (2009). Situational Maturity Models as Instrumental Artifacts for Organizational Design, Proceedings of the 4th International Conference on Design Science Research in Information Systems and Technology (DESRIST '09), Article No. 22.

North, K. \& Hornung, T. (2003). Benefits of knowledge management - results of the German Award "Knowledge Management 2002", Jurnal of Universal Computer Science, 9(6), 463-471.

O'Dell, C., Grayson, C., \& Essaides, N. (1998). If only we knew what we know: The transfer of internal knowledge and best practice, Free Press, New York, USA.

Oliveira, M., Pedron, C.D., Romão, M., \& Becker, G.V. (2011). Proposta de um modelo de matu ridade para Gestão do Conhecimento: KM3, Revista Portuguesa e Brasileira de Gestão, 10(4), 14-25.

Oliveira, M., \& Pedron, C.D. (2014). Maturity Model fro Knowledge Management and Stategic Benefits, Proceedings of the 15th European Conference on Knowledge Management (ECKM2014), 748-756. 
Paulk, M.C., Curtis, B., Chrissis, M.B., \& Weber, C.V. (1993). Capability Maturity Model, Version 1.1, School of Computer Science at Research Showcase @ CMU, Carnegie Mellon University, USA.

Pee, L.G., \& Kankanhalli, A. (2009). A model of organizational knowledge management maturity based on people, process, and technology, Journal of Information and Knowledge Management, 8(2), 1-21.

Petter, S., DeLone, W., \& McLean, E. (2008). Measuring information systems success: models, dimensions, measures, and interrelationships, European Journal of Information Systems, 17, 236-263.

Ragab, M.A.F., \& Arisha, A. (2013). Knowledge management and measurement: a critical review, Journal of Knowledge Management, 17(6), 873-901.

Robinson, H.S., Anumba, C.J., Carrillo, O.M., \& Al-Ghassani, A.M. (2006). STEPS: a knowledge management maturity roadmap for corporate sustainability, Business Process Management Journal, 12(6), 793-808.

Seddon, P.B., Staples, S., Patnayakuni, R., \& Bowtell, M. (1999). Dimension of Information System Success, Communications of the Association for Information System, 20(2), 2-61.

Seddon, P.B. (1997). A Respecification and Extension of the Delone and McLean Model of IS success, Information System Research, 8(3), 240-253.

Sedera, D., \& Tan, F. (2005). User Satisfaction: An Overarching Measure of Enterprise System Success, Proceedings of Pacific Asia Conference on Information Systems (PACIS 2005), Bangkok, Thailand: July 7-10, Paper 80.

Simpson, J.A., \& Weiner, E.S.C. (1989). The Oxford English dictionary, Oxford University Press, Oxford, UK.

Trkman, P., \& DeSouza, K. (2012): Knowledge Risks in Organizational Networks: An Exploratory Framework, The Journal of Strategic Information Systems, 21(1), 1-17.

Wulf, J., Winkler, T.J., \& Brenner, W. (2015). Measuring IT Service Management Capability: Scale Development and Empirical Validation, Proceedings of Wirtschaftsinformatik 2015, Paper 43.

Zviran, M., \& Erlich, Z. (2003). Measuring IS User Satisfaction: Review and Implications, Communications of the Association for Information Systems, 12(5), 81-103.

\section{Author's Biography}

Boštjan Delak, Ph.D, CISA, CIS, is a senior consultant at ITAD - Audit and Advisory, Ljubljana, Slovenia. He is a certified information system auditor and certified information security manager, he is also assistant professor at the Faculty of Information Studies - Novo mesto, Slovenia and at the University of Maribor - Faculty of Electrical Engineering and Computer Science - Maribor, Slovenia. He is lecturing: IS auditing, Fundamentals of Information Security and Strategic planning. His research interests are: IS due diligence, IS analysis and Knowledge management. 